\title{
Survey Evaluation of HIV/AIDS Prevention Awareness Campaign Use of Kirkpatrick Model
}

\author{
Afshin Bahmani ${ }^{1, *}$ \\ ${ }^{1}$ Assistant Professor of Health Education, Department of Public Health, Faculty of health, Kurdistan University of Medical Sciences, Sanandaj, Iran \\ * Corresponding author: Afshin Bahmani, Department of Public Health, Faculty of health, Kurdistan University of Medical Sciences, \\ Sanandaj, Iran. Tel: +988733286654; Email: afshin.bahmani@muk.ac.ir
}

Received 2021 Aygust 21; Revised 2021 October 23; Accepted 2021 November 15.

\section{Abstract}

Background: Acquired immunodeficiency syndrome (AIDS) is a pandemic and a health challenge in the world, posing a serious risk to people from all walks of life. Awareness Campaign has been increasingly used in recent years to convey persuasive messages to perform specific behaviors in the target group. The present study aimed to determine the effectiveness of AIDS prevention and awareness campaign in students using Kirkpatrick's Evaluation Model.

Methods: This cross-sectional study was conducted in border areas of Sarvabad City, Iran, in 2018. A total of 564 high school students were randomly selected. This research was performed based on the Kirkpatrick model which considers the effectiveness of training programs in four levels of reaction, learning, behavior, and results. The required data were collected by a questionnaire based on the Kirkpatrick model. The media used in this campaign included: banners, pamphlets, videos, and training by health experts. Data were analyzed in SPSS software (version 20).

Results: The most attractive media used in the awareness campaign for participants were training provided by health professionals (speech and Q\&A session), as well as educational videos, pamphlets, and banners, respectively. Based on the results, students' awareness and behavior significantly improved after the campaign by $51.6 \%$ and $25.6 \%$, respectively ( $\mathrm{P} \leq 0.00)$.

Conclusion: As evidenced by the results of the present study, the Kirkpatrick model was effective and can be employed to evaluate the awareness campaign since it demonstrates the positive changes caused by training in reaction, learning, and behavior. Therefore, effectiveness evaluation in all subjects needed to be improved through the implementation of optimizing training design.

Keywords: AIDS, Awareness campaign, Evaluation, Kirkpatrick model
\end{abstract}

\section{Background}

Acquired Immune Deficiency Syndrome (AIDS) is a deadly viral disease that is highly contagious and weakens the immune system. The human immunodeficiency virus (HIV) is one of the most dangerous viruses known in the world, posing a serious threat to the health and economy of human societies in terms of high mortality rate and high cost of care. It is of paramount importance as a social, cultural, and behavioral phenomenon, with teenagers being at a higher risk of developing this disease (1). The AIDS infection usually starts at the age of 25 and is the second leading cause of death in the world at a young age(2) .

By the end of 2019, the number of people living with HIV in the world was 38 million, and by the end of this year, 1,700,000 new cases of HIV were identified. In the same year, 690,000 people died of HIV/AIDS, out of whom 300,000 cases were female and 390,000 individuals were male. According to the report of the Ministry of Health, Treatment and Medical Education in Iran, by the end of 2019, 4,1496 people were infected with HIV, out of whom 237 cases died (3). Today, the world is experiencing the great crisis of HIV/AIDS, which is undoubtedly the greatest human complication since World War II (4).

Iran is one of the countries at the risk of AIDS infection(5), and it is predicted that the highest increase in the burden of diseases by 2025 in Iran will be related to the growth of HIV/AIDS (6). Therefore, according to the World Health Organization (WHO), Iran is one of the most high-risk countries in the world and the Middle East in terms of AIDS infection (7). Although the awareness of society, especially the youth, about the prevention of HIV transmission has increased, the youth and teenagers are more exposed to insufficient knowledge about this disease (8). With these interpretations, if we do not continue to seriously educate and prevent the transmission of AIDS, we will face a serious crisis regarding AIDS in the near future (9) .

Nonetheless, efforts and measures implemented to increase public awareness of modes of HIV transmission, methods of prevention, and health measures in many European and American countries have reduced the occurrence rate of the disease in those areas (10). Health education is the key to any healthy activity and one of the main foundations of health promotion that leads to opportunities for growth and development (11). Communities need proper health behavior training in order to maintain health promotion and avoid diseases, especially AIDS, and it is effective in the absence of treatment and vaccines. Therefore, the WHO has declared education to be the only effective way against AIDS and believes 
that vulnerable groups should be given priority in health programs (7). In this regard, schools are considered one of the key places for health promotion. The value of training programs depends on the effectiveness of these programs and increasing their effectiveness with the proper use of correct training methods (1) .

One of the teaching and information transfer methods is the awareness campaign which refers to a set of information, communication, and training activities using multiple and diverse information channels in order to convey messages to a certain population in a given time period, along with the goals of the program (12). It can be performed using a variety of media, and it tends to inform people about the risks of negative health behaviors and how to avoid or reduce their adverse effects (13). An awareness campaign is used to increase awareness of society in various fields of public health. Effective examples of awareness campaigns are the prohibition of smoking in different societies .

Progressive training approaches as major components of intervention strategies are increasingly considered in promoting and encouraging society to leave risky behaviors associated with health (14). Currently, the quality of training and its effectiveness are the most important concerns of the education system and decision-makers in the development of a country (15). Training evaluation as one of the most important programs provides useful information on the design and review of a system (16). In fact, the evaluation of training effectiveness provides managers and employees with a clear picture of the quality and quantity of training activities. It also equips planners and teaching staff to be aware of the pros and cons of the program (17). It is believed that evaluation of training effectiveness is more important in the design and implementation of training (18) .

One of the most well-known and widely used evaluation models for training and development programs is the four-level evaluation model by Donald Kirkpatrick (19). This model evaluates reaction, learning, behavior, and results. Reaction (attitude and satisfaction) is how participants feel about the training program. Learning (knowledge) determines the extent to which learners learn skills, techniques, and facts taught during training. Behavior refers to the degree of changes caused by participating in training courses. Results indicate the extent to which the considered goals are achieved (16). This model measures the effectiveness of a training course (20).

Sarvabad is a border city in the southwest of Kurdistan province near Iraq. Therefore, the possibility of traveling to neighboring countries through land borders highlights the necessity of increasing information on preventable diseases among people, especially high-risk groups. In light of the aforementioned issues, the present study aimed to determine the effectiveness of AIDS prevention and awareness campaign in students aided by Kirkpatrick's Evaluation Model.

\section{Materials}

This cross-sectional study aimed to evaluate AIDS prevention and awareness campaign in secondary schools of a border area in Sarvabad in 2018. The participants included 564 students in six schools (four boys schools and two girls schools). They were selected by random cluster sampling from two border districts of Sarvabad. The inclusion criteria entailed the students who volunteered and were interested in participating in the study. On the other hand, the exclusion criteria were unwillingness to participate in classes and absence from more than one session. The awareness campaign lasted for months, starting from January 19 to April 21, 2018. The media used in this campaign included: 1) a banner designed by the Ministry of Health and Medical Education, 2) a pamphlet designed by the Department of Communicable Diseases Prevention Management, 3) two instructional videos about the disease and symptoms and disease prevention, and 4) two 4-hour training sessions by health experts.

The data were collected through a researchermade questionnaire and validity was assessed by the relevant experts and its content and face validities were confirmed using the views of five health professionals. Cronbach's alpha test was used to calculate the reliability. The general validity and reliability of the questionnaire were reported to be $0.84 \%$ and $0.86 \%$, respectively. The awareness campaign was evaluated based on the Kirkpatrick model with three levels. The total number of items in the questionnaire was 31. At the first level, the reaction was measured through a 12-item questionnaire. They are scored on a five-point Likert scale (strongly agree, agree, disagree, disagree, strongly disagree). Finally, the practice was measured quantitatively .

This questionnaire measured the attractiveness of educational media, their relevance to the content and subject of the campaign, and their effect on learning. At the second level, learning was measured through pretest and posttest in 12 items. At the third level, behavioral changes or performance were evaluated by a 7-item questionnaire through pretest and posttest. The fourth stage of the model is not examined in this study. The data were analyzed in SPSS software (version 20) using descriptive statistics (absolute and relative frequency, mean and standard deviation), as well as Mann-Whitney U test and t-test. The approval of the Department of Education, principals, and parents of students was obtained to conduct the study. Moreover, the information extracted from the encoded questionnaires was kept confidential. 


\section{Results}

Out of 564 participants, 189 (33.5\%) cases were male and 375 subjects $(66.5 \%)$ were female (mean age:15.9 \pm 1.05$)$. In the first level of the model (reaction), the most attractive media used in the awareness campaign for participants included educational videos, training provided by health professionals, pamphlets, and banners, respectively (Figure 1). Regarding the relevance of educational media to the subject of the campaign, students believed that educational videos and face-to-face training were more relevant than other methods (Figure 2). In terms of the effect of educational materials on learning, students believed that face-toface training was more effective and the banner was the least effective method (Figure 3). In this study, $52.2 \%$ of students found awareness campaigns a helpful method for information transfer, $38.5 \%$ of cases did not consider the campaign a sufficient and complete method, and $9.3 \%$ of subjects were opposed to the use of this method for conveying messages and information.

Regarding the second and third levels of the model

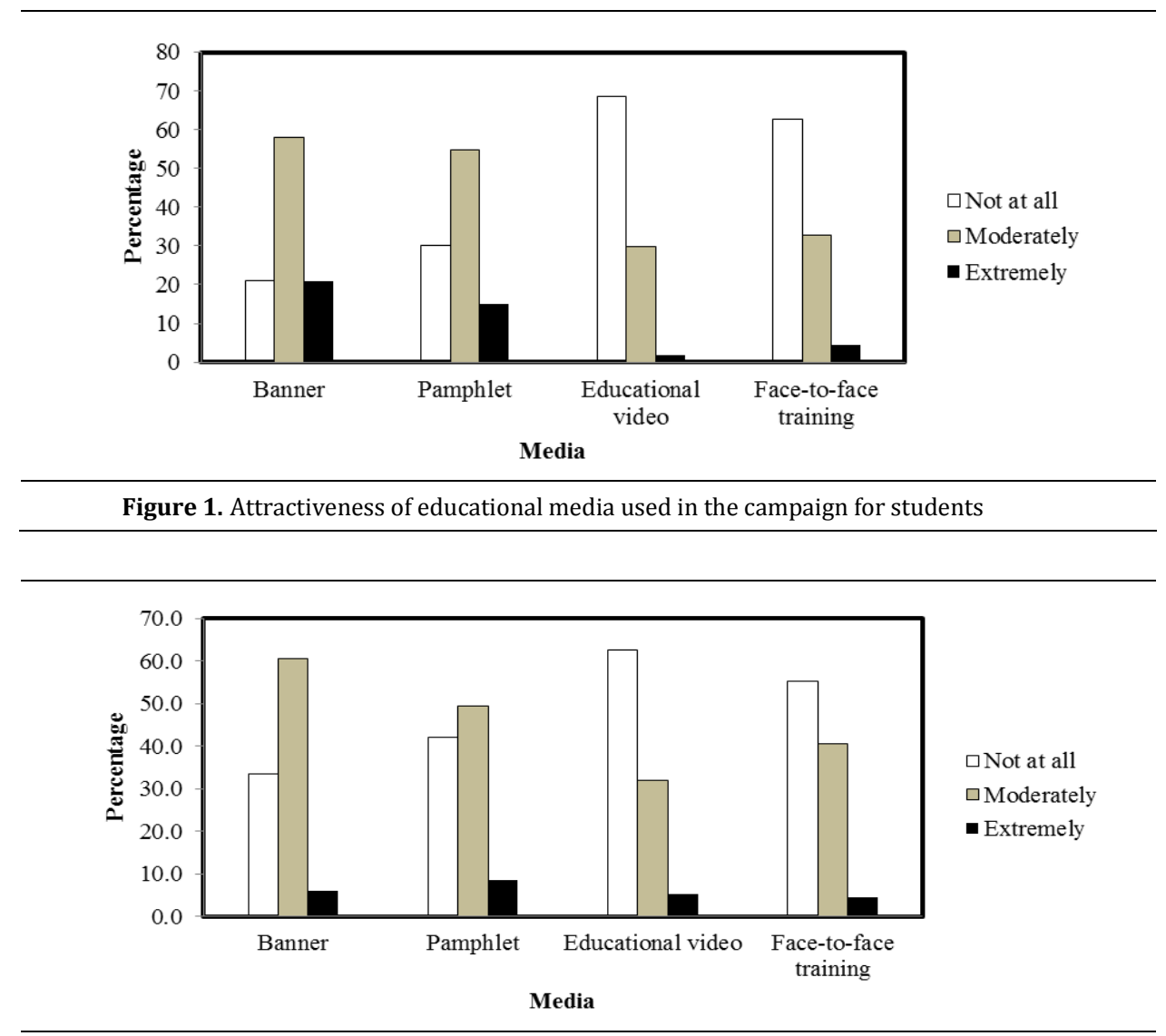

Figure 2. Relevance of media to subject of the campaign for students

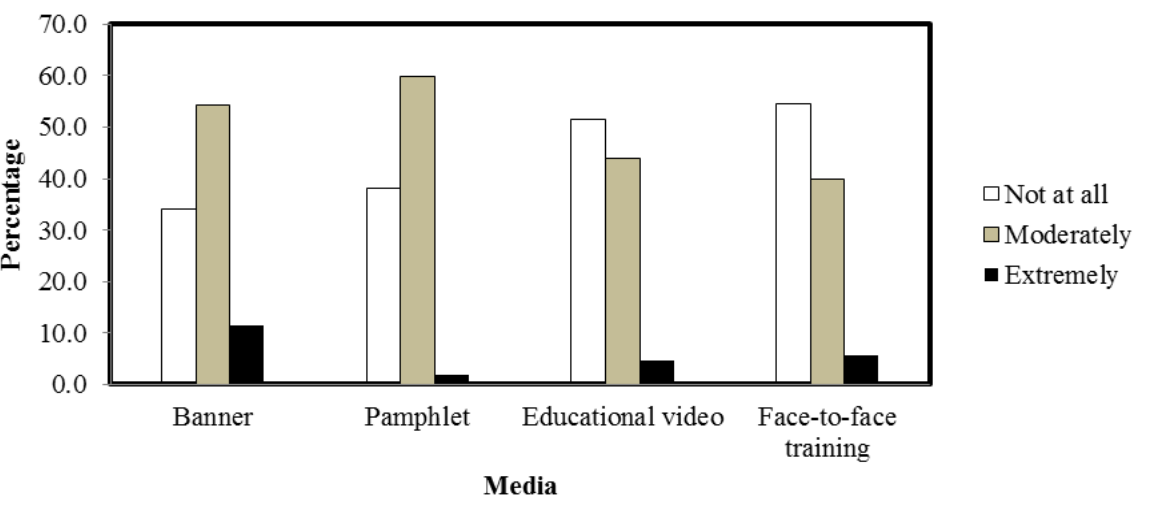

Figure 3. Effect of educational media used for the campaign for students 
Bahmani A.

Table 1. Frequency of responses to questions measuring awareness before and after the campaign

\begin{tabular}{lcccccc}
\hline & \multicolumn{3}{c}{ Before the campaign } & \multicolumn{3}{c}{ After the campaign } \\
\cline { 2 - 7 } & True & I don't know & False & True & I don't know & False \\
\hline Symptoms of AIDS & $64 \%$ & $28 \%$ & $8 \%$ & $83 \%$ & $10 \%$ & $7 \%$ \\
Transmission of AIDS & $82 \%$ & $14 \%$ & $4 \%$ & $89 \%$ & $7 \%$ & $4 \%$ \\
Risk factors of AIDS & $33 \%$ & $16 \%$ & $51 \%$ & $45 \%$ & $8 \%$ & $47 \%$ \\
Treatment of AIDS & $40 \%$ & $38 \%$ & $22 \%$ & $73 \%$ & $14 \%$ & $13 \%$ \\
Factors which are t involved in preventing AIDS & $40 \%$ & $27 \%$ & $33 \%$ & $52 \%$ & $21 \%$ & $27 \%$ \\
\hline Factors which are not involved in developing AIDS & $32 \%$ & $35 \%$ & $33 \%$ & $54 \%$ & $21 \%$ & $25 \%$ \\
\hline
\end{tabular}

(learning and behavior), the questions related to the awareness and behavior of students were measured (Table 1 and 2). Based on the results, the awareness and behavior of students increased by $44.6 \%$ and $20.6 \%$, respectively, after the campaign (Table 3 ).
The results suggested that there was a significant relationship between awareness before and after the campaign $(\mathrm{P}<0.001)$. Moreover, there was a significant relationship between the behavior of students before and after the campaign $(\mathrm{P}<0.03)$.

\begin{tabular}{|c|c|c|c|c|c|c|}
\hline & \multicolumn{3}{|c|}{ Before the campaign } & \multicolumn{3}{|c|}{ After the campaign } \\
\hline & $\begin{array}{c}\text { Yes } \\
\text { often }\end{array}$ & $\begin{array}{c}\text { Yes } \\
\text { sometimes }\end{array}$ & No & $\begin{array}{c}\text { Yes } \\
\text { often }\end{array}$ & $\begin{array}{c}\text { Yes } \\
\text { sometimes }\end{array}$ & No \\
\hline I follow all precautions when going to the dentist. & $60 \%$ & $37 \%$ & $2 \%$ & $79 \%$ & $19 \%$ & $1 \%$ \\
\hline I follow all the precautions when going to the hairdresser. & $85 \%$ & $13 \%$ & $2 \%$ & $86 \%$ & $10 \%$ & $4 \%$ \\
\hline I observe all precautions when getting a tattoo. & $29 \%$ & $12 \%$ & $59 \%$ & $38 \%$ & $16 \%$ & $46 \%$ \\
\hline I visit the doctor if I feel any symptoms of Aides. & $23 \%$ & $53 \%$ & $24 \%$ & $40 \%$ & $49 \%$ & $11 \%$ \\
\hline I do not use a condom if I have sex. & $3 \%$ & $5 \%$ & $92 \%$ & $2 \%$ & $4 \%$ & $94 \%$ \\
\hline
\end{tabular}

Table 3. Mean scores of awareness and behavior of students before and after the campaign

\begin{tabular}{lcc}
\hline & Awareness & Behavior \\
\hline Before the campaign & $22.5 \pm 8.12$ & $39.1 \pm 5.27$ \\
After the campaign & $67.14 \pm 16.9$ & $59.7 \pm 7.13$ \\
\hline
\end{tabular}

\section{Discussion}

Evaluation is an essential process in human resource management and plays a major role in the productivity of health care organizations (21). As illustrated by the results of this study, AIDS Prevention Awareness Campaign based on the "Kirkpatrick model "was an effective program. In the first level, the "Kirkpatrick model " participants were satisfied about the content of the educational program and desirable educational facilities. Yoon et al. used the Kirkpatrick model to review the evaluation of a continuing professional development training program for physicians and physician assistants in hospitals in Laos, and participants were satisfied with training and participation in the course (22).

Other studies examined the satisfaction of participants in a program at the Department of Medicine and Health at the first level of the "Kirkpatrick model ", and all of them gave positive reactions to the received training $(23,24)$. In this study, participants' learning increased at levels two and three of the "Kirkpatrick model "after training. In their study, Nega et al. assessed the school curriculum of medicine and pharmacy using the Kirkpatrick model, and both of these patterns (learning and behavior) were positive (25). Akbari et al. evaluated the training program of physicians in Vietnam, and the results showed that at levels one, they had a favorable reaction and at levels two and three, good progress was made (26).

Participants' learning was also enhanced in numerous other studies based on the "Kirkpatrick model"in clinical settings and different groups of medical sciences $(27,28)$. In this study, positive changes were made in the learning and behavior of students to prevent AIDS. Randolph et al. reviewed 18 awareness campaigns and found that awareness campaign was effective for learning in $67 \%$ of cases and on behavior in $89 \%$ of cases (29). The mentioned study pointed to a significant relationship between modification and promotion of AIDS preventive behavior before and after the campaign. Similar studies conducted on awareness campaigns for the promotion of physical activity found significant modifications in the promotion of physical activity in 7 out of 15 studies reviewed $(28,29,30,31,32)$.

This study evaluated the effectiveness of an awareness campaign by pretest and posttest. Randolph et al. reviewed 13 studies conducted on the evaluation of awareness campaigns and reported that $8(61.5 \%)$ studies used the pretest and posttest and 5 (29\%) other studies used a comparative group (29). Among the limitations of this study, we can refer to students' self-report in 
completing the questionnaire, coordination with them in completing the questionnaire, and time limitation for evaluating the fourth stage of Kirkpatrick model and its three stages.

It is recommended that training processes be evaluated to determine the effectiveness of different components of the training and development program. The results of the present study pointed out that the "Kirkpatrick model "can identify many important points that can be useful in training and awareness campaigns. Therefore, planners and policymakers in the field of education need to have a thorough knowledge of evaluation models to propose educational plans in the future.

\section{Acknowledgments}

The authors' deepest appreciation goes to the health network of Sarvabad and Research Department of the Kurdistan University of Medical Sciences.

\section{References}

1. kaarazi s, Peyman N. Effect of educational interventions based on the health belief model on the promotion of aids preventive behaviors among female High School Students in Mashhad, Iran, in 2016. Health Res J. 2017; 13(1):14-18. doi: 10.22122/jhsr.v13i1.2899.

2. Heshmati H, Behnampour N, Pirzadeh A. A Study on HighSchool Students' Knowledge about the AIDS in Ashkhane City, Iran, 2012. Health Serv Res. 2016; 12(1):1-5.

3. Najafi Z, Taj L, Dadras O, Ghadimi F, Moradmand B, SeyedAlinaghi S. Epidemiology of HIV in Iran. Curr HIV Res. 2020;18(4):228-236.

4. Vakili M, Babakhani L, Sharifi S, Moazen A, Mehrabi Z, Kamali K, et al. Development and Psychometric Analysis of A 44-Item HIV/AIDS Knowledge Scale: An Iranian Cultural and Population Based Study. 2018;14(2):116-125.

5. McGuire, S., 2016. World cancer report 2014. Geneva, Switzerland: World Health Organization, international agency for research on cancer, WHO Press, 2015. Advances in nutrition, 7(2):418-419.

6. Vatanchi E, Larki kh, Hadizadeh talasaz M, Manouchehri torshizi Z, Mirzaiinagm abadi A. A review of HIV/AIDS prevention interventions in Iran. Navid No. 2018; 21(66):6376. doi: 10.22038/nnj.2018.33528.1128.

7. Secretariat NAC. Islamic Republic of Iran AIDS Progress Report. Ministry of Health and Medical Education Tehran. 2015.

8. Soltani K, Tavafian S, Vakili M. Influence of educational program based on Health Belief Model in health beliefs in AIDS among students. Armaghane-danesh. 2014; 19 (9): 797-807.

9. Besoain F, Perez-Navarro A, Caylà JA, Aviñó CJ, deOlalla PG. Prevention of sexually transmitted infections using mobile devices and ubiquitous computing. Int $J$ Health Geogr. 2015; 14(1):1-12. doi: 10.1186/s12942-015-0010-z. [PubMed: 25935151].

10. Roshandel S. Opportunities and challenges of mobile phone technology for HIV treatment and prevention. J Mod Med Info Sic. 2017; 12(4):56-66. doi: 10.1007/s11904-015-0289-1. [PubMed: 26412082].

11. Larki M, Taffazoli M, Latifnejad-Roudsari R, Shakeri MT,Babaee A. The Effect of a Training Program Based on the Theory of Planned Behavior (TPB) on Sexual High- Risk 13. Behavioral Intentions in Female Prisoners, Vakil Abad Prison, Mashhad, Iran, 2013.J Kerman Univ Med Sic. 2016;23(4):497-514.

12. Turner S, Chase DL, Milne R, Cook A, Hicks NJ: The health technology assessment adaptation toolkit: description and use. Int J Technol Assess Health Care. 2009, 25 (Suppl 2): 37-41.
13. Lund J, Aaro L. Accident prevention. Presentation of a model placing emphasis on human, structural and cultural factors. Safety Science. 2004; 42(4): 271-324. doi: :10.1016/S09257535(03)00045-6.

14. Awopetu O, Brimacombe M, Cohen D. Fetal Alcohol Syndrome Disorder Pilot Media Intervention in New Jersey. Can J Clin Pharmacol. 2008; 26(15): e124-e131. [PubMed: 18299640].

15. Goudarzvand Chegini M. Ismail M. The Impact of IT Use on Training Effectiveness. J New Approaches Educ Res. 2012;2(3):1-24.

16. Hojjati H. Learning theories in Medical Sciences. Tehran: Publications Hakim Hydjy. 2013.

17. Methane M, Hassanzadeh R. The effectiveness of in-service training to the employees free of Sari. Educational Research University Bojnourd. 2009; 4(16): 160-180.

18. AkbariM, karimi M, Ayzanlou O. Educational Planning return pattern of medical education. Journal Horizons of Medical Education Development. 2011; 4(3): 27-33.

19. Smith, L. Continuing professional development and workplace learning and human resource development- the return on the investment. Libr Manag. 2004; 25(4): 233

20. Khorasani B, Doste H. Evaluating the effectiveness of training programs based on the return to capital. Iranian Journal of Engineering Education. 2012; 13(52):103-122.

21. Nikpeym N, Abed-Saeedi Z, Azargashb Z, Alavi-Majd H. A review of nurses 'performance appraisal in Iran. $J$ Promot. Manag. 2014; 3(1):74-83.

22. Yoon HB, Shin JS, Bouphavanh K, Kang YM. Evaluation of a continuing professional development training program for physicians and physician assistants in hospitals in Laos based on the Kirkpatrick model. J Educ Eval Health Prof. 2016; 13:21. doi: 10.3352/jeehp.2016.13.21 pmid: 27246494.

23. Paull M, Whitsed C, Girardi A. Applying the Kirkpatrick model: Evaluating an interaction for learning framework'curriculum intervention. Issues Educ. Res. 2016; 26(3):490-507.

24. Farjad S. The Evaluation Effectiveness of Training Courses in University by Kirkpatrick Model (Case Study: Islamshahr University). Proc Soc Behav Sci. 2012; 46:2837-41. doi: 10.1016/j.sbspro.2012.05.573

25. Nga le TQ, Goto A, Trung TT, Vinh NQ, Khue NT. Capacity building toward evidence-based medicine among healthcare professionals at the university of medicine and pharmacy, ho chi minh city, and its related institutes. Japan Med Assoc J. 2014; 57(1):49-55. [PubMed :25237279].

26. Akbari M, Dorri S, Mahvar T. The effectiveness of in-service training on cardiopulmonary resuscitation: Report of first and second levels of Kirkpatricks Model. J Dev Strategies Med Educ. 2016; 3(1):67-72

27. Rojo E, Maestre JM, Diaz-Mendi AR, Ansorena L, Del Moral I. Innovation in healthcare processes and patient safety using clinical simulation. Rev Calid Asist. 2016; 31(5):267-78. doi: 10.1016/j.cali.2015.12.008. [PubMed: 26965531].

28. Hojjati H, Mehralizadeh Y, Farhadirad H, Alostany S, Aghamolaei M, Eghbal A, et al. Assessing the effectiveness of training outcome based on Kirkpatrick Model: Case study. Q J Nurs Manag. 2013; 2(3):35-42.

29. Randolph KA, Whitaker P, Arellano A. The unique effects of environmental strategies in health promotion campaigns: a review. Eval Program Plan. 2012; 135(3):344-53. doi: 10.1016/j.evalprogplan.2011.12.004. [PubMed: 22265758].

30. De Cocker KA, De Bourdeaudhuij IM, Brown WJ, Cardon GM. Effects of "10,000 steps Ghent": a whole-community intervention. Am Journal Prev Med. 2007;33(6):455-63. doi:10.1016/j.amepre.2007.07.037. [PubMed: 18022061].

31. Reger-Nash B, Bauman A, Booth-Butterfield S, Cooper L, Smith $\mathrm{H}$, Chey T, Simon KJ, et al. Wheeling walks: evaluation of a media-based community intervention. Fam Community Health. 2005;28(1):64-78.doi: 10.1097/00003727-200501000-00009. [PubMed: 15625507].

32. Merom D, Miller Y, Lymer S, Bauman A. Effect of Australia's Walk to Work Day campaign on adults' active commuting and physical activity behavior. Am J Health Promot. 2005; 19(3):159-62. doi: 10.4278/0890-1171-19.3.159. [PubMed: 15693344]. 